\title{
Sensitivity of Watershed Runoff under Humid Conditions to Potential Climate Variations
}

\author{
Jozsef Szilagyi ${ }^{1}$; Marc B. Parlange ${ }^{2}$; Jonathan A. Patz ${ }^{3}$; and Thaddeus K. Graczyk ${ }^{4}$
}

\begin{abstract}
A semidistributed watershed model is applied over the Mahantango Creek catchment in Pennsylvania to estimate future changes in direct runoff under 22 different climate scenarios. It is shown how different subcatchments of the watershed may respond to possible changes in the precipitation and temperature regimes. Subcatchments with the most unfavorable future runoff responses can be identified where possible changes in land use management practices may be suggested.
\end{abstract}

DOI: $10.1061 /(\mathrm{ASCE}) 0733-9372(2002) 128: 7(635)$

CE Database keywords: Watersheds; Humidity; Surface runoff; Climatic changes; Land usage; Sensitivity analysis.

\section{Introduction}

Concern over global warming and consequences for regional hydrologic impacts are growing. A new study by the U.S. National Research Council (NRC) (2000) states that the Earth's surface temperature has risen by $0.4-0.8^{\circ} \mathrm{C}$ in the last century, of which a rise of $0.25-0.4^{\circ} \mathrm{C}$ has been observed in just the last 20 years. Increasing temperatures can lead to an accelerating hydrologic cycle (i.e., to increased precipitation and evaporation levels) but with great regional differences (Karl et al. 1996; Manabe 1997; Brutsaert and Parlange 1998). Karl et al. (1996) demonstrated for most parts of the U.S. an increasing trend in annual precipitation over the last century, although some parts (mostly in the west) have had a decrease in rainfall. Despite all these apparent regional differences in annual precipitation, an increase in precipitation variability is universally discernible over the contiguous U.S. (Houghton et al. 1996).

A prolonged change in the precipitation and temperature regimes will certainly have an effect on future watershed runoff patterns, which, in turn, will affect soil erosion rates, pollution by industrial and wastewater effluents, and pathogen loading to streams, just to mention a few possible direct consequences (Fraser et al. 1998). From a drinking water management standpoint this last prospect is of special concern in light of recent findings (Graczyk et al. 2000). Rainfall and runoff have been implicated in individual waterborne disease outbreaks in the United

\footnotetext{
${ }^{1}$ Assistant Professor, Univ. of Nebraska-Lincoln, Conservation and Survey Division, Lincoln, NE 68588-0517. E-mail: jszilagyil@unl.edu

${ }^{2}$ Professor, Dept. of Geography and Environmental Engineering, Johns Hopkins Univ., Baltimore, MD 21218-2686.

${ }^{3}$ Assistant Professor, Dept. of Environmental Health Sciences, Johns Hopkins School of Hygiene and Public Health, Baltimore, MD 21205.

${ }^{4}$ Associate Scientist, Dept. of Molecular Microbiology and Immunology, Johns Hopkins Univ., Baltimore, MD 21205.

Note. Associate Editor: Robert G. Arnold.Discussion open until December 1, 2002. Separate discussions must be submitted for individual papers. To extend the closing date by one month, a written request must be filed with the ASCE Managing Editor. The manuscript for this paper was submitted for review and possible publication on April 12, 2001; approved on November 13, 2001. This paper is part of the Journal of Environmental Engineering, Vol. 128, No. 7, July 1, 2002. (CASCE, ISSN 0733-9372/2002/7-635-642/ $\$ 8.00+\$ .50$ per page.
}

Kingdom (U.K. Dept. of the Environment 1990), Montana (Weniger et al. 1983), and, the largest one, in Milwaukee, in 1993, where an estimated 403,000 cases of intestinal illness and 54 deaths were reported (MacKenzie et al. 1994; Hoxie et al. 1997).

Currently, general circulation models (GCMs) can be used to estimate changes in climatic variables for various increasing $\mathrm{CO}_{2}$ scenarios only over large areas, such as continents (Wilks 1992). There are downscaling techniques being applied today to convert GCM predictions to regional scale (Easterling 1999), but these approaches still lack the temporal resolution needed in hydrologic impact studies. Also, the high spatial variability of past precipitation trends suggests that these models are probably inadequate for the purpose of impact studies, where future expected behavior of climatic variables is needed as input to models dealing with generally small geographic areas, such as a particular watershed. One common approach adopted by climate change impact analysts is to consider a wide range of possible scenarios of future climate (Wilks 1992; Katz 1996; Mearns et al. 1997). A typical way of achieving this goal is to take existing records of climatic variables (typically temperature and precipitation records) and adjust them to reflect possible future climate changes (Wilks 1992). While in the last century over the conterminous U.S. annual mean surface temperatures and precipitation variance expressed a generally increasing trend, there is no guarantee that these trends will continue in the near future, even more so because mean annual temperatures in the last century show an actually decreasing trend over large regions within the continental U.S. (Karl et al. 1996). As a result, impact studies need to consider both increases and decreases in the mean and variability of climate variables (Mearns et al. 1997).

In this paper we use the approach of Mearns et al. (1997) in constructing mean and variance changes in recorded precipitation and temperature time series for the Mahantango Creek watershed in South-Central Pennsylvania within the Susquehanna River basin. A semidistributed watershed model (Szilagyi and Parlange 1999 ) is used to transform changes in the climatic variables (precipitation, temperature) to direct runoff distributed within the catchment. These simulated mean annual runoff values will be analyzed and compared between subcatchments to identify runoff response within the catchment with changes in the precipitation and temperature regimes. Finally, subcatchments with the largest/ smallest expected changes in runoff response will be identified to 
possibly assist in future land use management planning in the watershed.

\section{Precipitation-Temperature Models}

Present day climate is represented by time series of both hourly and daily precipitation as well as daily mean temperature values. These series are considered as representations of a stochastic process with parameters estimated from the observed values. A climate change scenario is produced by adjusting the parameters of these stochastic processes in accordance with the assumed future changes in the statistics of these time series (Wilks 1992). Then 30 years of daily (and consequently hourly) precipitation as well as daily mean temperature values are generated in the Monte Carlo sense to represent both present and altered climates. The derived time series will become inputs later in the watershed model to obtain direct runoff time series distributed within the catchment. Below we follow Wilks (1992) and Katz and Parlange (1995) to construct first the daily and then the hourly time series.

\section{Simulation of Daily Values}

The model used here is a version of a stochastic simulation of daily weather variables first proposed by Richardson (1981) and refined since by several authors (Katz 1996; Parlange and Katz 2000). The variables are precipitation occurrence and amount as well as mean temperature.

Precipitation occurrence is assumed to follow a two-state, first-order Markov chain with transition probabilities $P_{01}$, the probability that a wet day follows a dry day; and $P_{11}$, the probability that a wet day comes after a previous wet day. These transition probabilities are allowed to follow a seasonal cycle, which means that different months of the year have different values for the transition probabilities. For each month of the year the probability of a wet day is obtained by (Katz 1996)

$$
P_{w}=\frac{P_{01}}{1+P_{01}-P_{11}}
$$

while the so-called persistence parameter is given by

$$
d=P_{11}-P_{01}
$$

It is also a function of the month. Precipitation amount $(r)$ on a wet day is assumed to follow a gamma distribution

$$
f(r)=\frac{(r / b)^{a-1} \exp (-r / b)}{b \Gamma(a)}
$$

with parameters $a$ (the shape parameter) and $b$ (the scale parameter). The shape parameter can be estimated as $a=m / b$, where $m$ is the mean daily precipitation on wet days in a given month; while the scale parameter is estimated as $b=\sigma a^{-1 / 2}$, where $\sigma$ is the standard deviation of the precipitation amounts on wet days in a given month. The daily weather generator thus has four parameters for each month.

The maximum likelihood estimate of the transition probabilities is

$$
\hat{P}_{i j}=n_{i j} / n_{i}
$$

where $n_{i j}$ denotes the number of times a transition from state $i$ to state $j$ occurs, and $n_{i}=n_{i 0}+n_{i 1}$ (Katz and Parlange 1995). Since these monthly transition probabilities may follow seasonal cycles we smoothed the logistic transform of the estimated values by a cosine wave in the form (Woolhiser et al. 1993; Katz and Parlange 1995)

$$
\begin{gathered}
\ln \left(\frac{\hat{P}_{i 1}}{1-\hat{P}_{i 1}}\right)= \\
i=0,1 ; j=1, \ldots, 12
\end{gathered}
$$

where the unknown parameters $A_{i}, B_{i}$, and $C_{i}$ were obtained via weighted least squares with the weights given by (Katz and Parlange 1995)

$$
g_{i}=n_{i} . \hat{P}_{i 1}\left(1-\hat{P}_{i 1}\right), \quad i=0,1
$$

again, a function of the month. The smoothed monthly transition probabilities were finally obtained by inverting the logistic transformation.

For changing the parameters according to the prescribed climate scenario, the following relationships were utilized:

$$
m\left(S_{N}\right)=N P_{w} a b
$$

where $m=$ mean; $S_{N}=$ monthly precipitation sum of $N$ days; and

$$
\operatorname{Var}\left(S_{N}\right) \approx N P_{w} a b^{2}\left[1+a\left(1-P_{w}\right) \frac{1+d}{1-d}\right]
$$

where Var denotes the variance of the monthly precipitation sums (Wilks 1992).

The daily mean temperature values were represented by a firstorder autoregressive process (Wilks 1992)

$$
T_{i}^{*}(t)=\rho T_{i}^{*}(t-1)+\varepsilon(t), \quad i=0,1
$$

where $T_{i}^{*}=$ standardized daily mean temperature for wet $(i=1)$ and dry $(i=0)$ days of the month; $t=$ day of the month; $\rho$ $=$ autocorrelation value at lag one; and $\varepsilon=$ normally distributed random variable with zero mean and standard deviation, $\sigma=(1$ $\left.-\rho^{2}\right)^{1 / 2}$ (Box et al. 1994). Note that $\rho$ is a function of the month and assumed to be the same for wet and dry days (Wilks 1992). The monthly means and standard deviations in the standardization

$$
T_{i}^{*}=\frac{T_{i}-m_{i}}{\sigma_{i}}, \quad i=0,1
$$

generally exhibit a well-defined annual cycle; thus their estimated values were smoothed by a cosine wave (Wilks 1992) similar to Eq. (5), except that this time no logistic transformation or weighting was required since each month has roughly the same number of observations, unlike the number of wet days each month may have on average in Eq. (4). For generating daily mean temperature values Eq. (9) was used, and the final values were obtained by inverting Eq. (10) with the smoothed means and variances separately for wet and dry days. The following equation was used when modification of the interannual variance was required (Wilks 1992; Mearns et al. 1997) under a given climate scenario:

$$
\operatorname{Var}(\langle T\rangle) \approx \frac{\sigma_{d}^{2}(1+\rho)}{N(1-\rho)}
$$

where $\langle T\rangle=$ monthly mean temperature; and $\sigma_{d}=$ standard deviation of the mean daily temperature values for a certain month of the year.

\section{Structure of Hourly Precipitation Generator}

Hourly precipitation transition probabilities and amounts are assumed to be a function of the hour only and not of the month. Hourly transition probabilities can be treated similarly to daily transition probabilities with the obvious distinction between hours of the day and months of the year; thus the earlier equations 
remain valid with this in mind. The probability that the $h$ th hour of the day is wet can be obtained from the following recursion (Katz and Parlange 1995):

$$
\begin{gathered}
P_{w}(h+1)=P_{01}(h)+P_{w}(h)\left[P_{11}(h)-P_{01}(h)\right] \\
h=1, \ldots, 24
\end{gathered}
$$

with $P_{w}(25)=P_{w}(1)$, which poses a system of linear equations with 24 unknowns.

While on a daily time scale it is generally assumed that the daily precipitation amounts are independent, it is not so with hourly precipitation amounts. Before modeling hourly intensities a power transform of the values is generally required to allow for any skewness in their distribution (Katz and Parlange 1995)

$$
r^{*}(h)=[r(h)]^{p} \text { for some } p, 0<p<1
$$

where the power transformed intensities $\left(r^{*}\right)$ are assumed to follow a normal distribution. For choosing the correct $p$ value Hinkley's index (1977) is calculated for $p=1 / 2,1 / 4,1 / 8, \ldots$, etc.

$$
H_{p}=\frac{m-m d}{\sigma}
$$

and the $p$ retained, which results in the index value closest to zero (Katz and Parlange 1993). Here $m$ is the mean, $m d$ the median, and $\sigma$ the standard deviation of the hourly intensities. An optimum value of $p=0.5$ resulted with our data of 5 years of hourly precipitation at Klingerstown in the Mahantango watershed.

The transformed and then standardized intensities within a given wet spell are modeled as a first-order autoregressive process, similar to the mean daily temperature values in Eq. (9). The autocorrelation coefficient is assumed to be independent of the hour of the day (Katz and Parlange 1995).

Before generating intensity values the transition probabilities were smoothed by a cosine wave, similar to Eq. (5) (except the obvious difference that the hours go from 1 to 24). The hourly mean $\left(m^{*}\right)$ and standard deviation $\left(\sigma^{*}\right)$ values of the transformed hourly intensities were also smoothed by a cosine wave in the form

$$
\begin{aligned}
& m^{*}(h)=A_{m}^{*}+B_{m}^{*} \cos \left(\frac{2 \pi h}{24}\right)+C_{m}^{*} \sin \left(\frac{2 \pi h}{24}\right) \\
& \sigma^{*}(h)=A_{\sigma}^{*}+B_{\sigma}^{*} \cos \left(\frac{2 \pi h}{24}\right)+C_{\sigma}^{*} \sin \left(\frac{2 \pi h}{24}\right)
\end{aligned}
$$

The parameters were obtained via weighted least squares using Eq. (6) for the transition probabilities and the equation $g_{1}^{*}(h)$ $=n_{1}$. $(h)$ for the means and standard deviations in Eqs. (15) and (16). A word of caution is that the standard deviations are computed about the cosine wave fitted to the mean hourly intensities and not about the individual hourly means (Katz and Parlange 1995). Note also that $\rho$ for the transformed and standardized hourly intensities is obtained by the smoothed values of the hourly means and deviations.

Figs. 1 and 2 display the observed (smoothed) and modeled hourly probabilities of dry-to-wet and wet-to-wet transitions as well as precipitation intensities and their standard deviations for the day at Klingerstown, $\mathrm{Pa}$.

\section{Coupling of Daily and Hourly Weather Generators}

The watershed model described below transforms the climate variables into runoff. The model runs on an hourly basis which is why an hourly precipitation generator is needed. To compare the
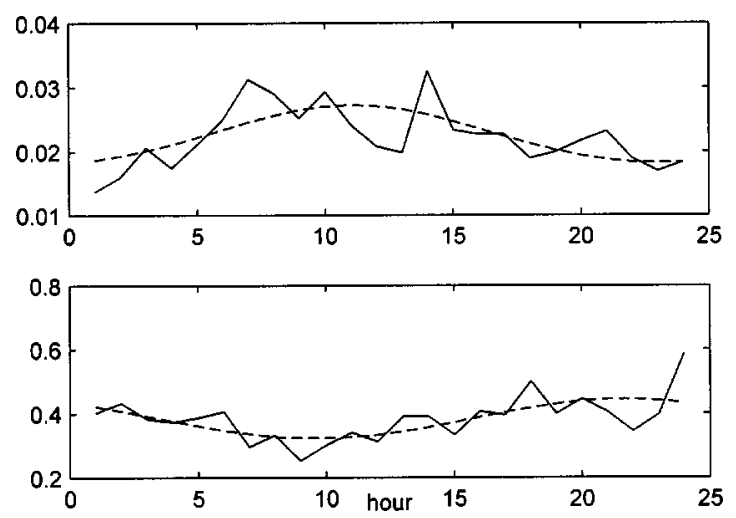

Fig. 1. Observed (and smoothed) and modeled (continuous line) hourly probabilities of daily dry-to-wet and wet-to-wet transitions, Klingerstown, Pa.

runoff response of the Mahantango Creek watershed under altered climate to the one under the present climate, first 30 years of daily precipitation values and then 30 years of daily mean temperatures, both meant to represent the present climate, were generated, the latter based on knowledge from the daily generated precipitation time series of whether a day was wet or dry. The present day weather generator used parameters obtained from 5 years of measured hourly precipitation for the hourly precipitation generation and 43 years of daily precipitation sums and mean temperature values measured at Newport, Pa., for the generation of daily weather variables. To link generated hourly precipitation intensities to generated daily values, 300 years of hourly precipitation intensities were generated and stored in a file in a daily structure. For each wet day from the daily weather generator the days from the hourly precipitation file were retrieved that had a daily sum (by cumulating the hourly intensities for the day) equal to the daily weather-generator-obtained value plus/minus a certain tolerance value. From the so obtained daily values of hourly intensities one realization was picked randomly and considered as the hourly distribution of intensities for the given wet day. This procedure provided us with a realization of 30 years of hourly precipitation intensities that was considered to be representative of the present day climate.

Fig. 3 displays the observed, fitted, and model-generated cumulative distribution functions (CDFs) of the daily precipitation amounts in June at Newport, Pa.
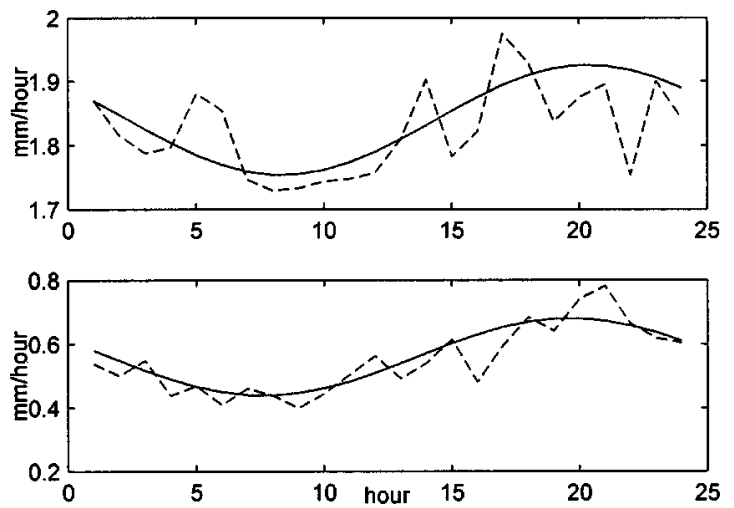

Fig. 2. Observed (and smoothed) and model-generated (intermittent line) hourly intensities and standard deviations, Newport, Pa. 


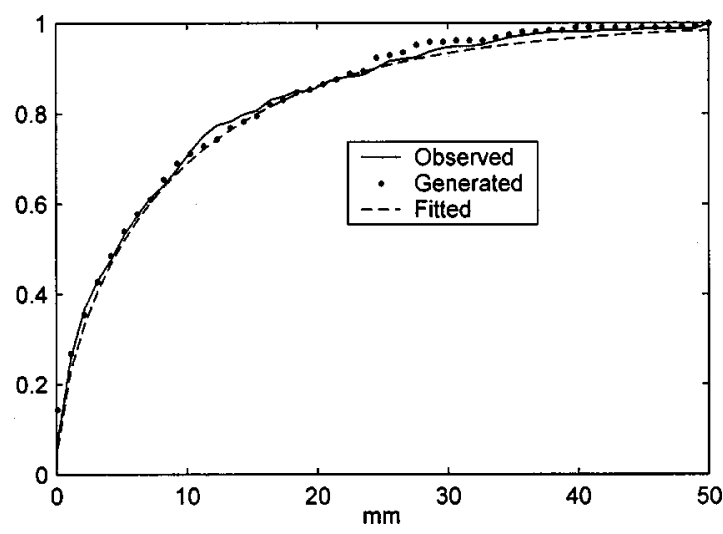

Fig. 3. Cumulative distribution functions of observed, fitted, and model-generated daily precipitation amounts for June, Newport, Pa.

\section{Description of Watershed Model}

The watershed model used in this study was published by Szilagyi and Parlange (1999). Here we summarize the basic components of the model. For a more complete description, please refer to the above publication. The model treats the watershed as a cascade of partially parallel nonlinear reservoirs including both overland and channel flow. Inputs to the model include hourly precipitation intensities, mean monthly temperatures, soil type, land-use/land-cover type, stream network, and elevation. The model has 19 parameters from which 12 can be obtained through Geographic Information System analysis and the application of the Brutsaert-Nieber technique (1977) of estimating aquifer parameters, both independent of the rainfall-runoff record. The model outputs are simulated direct runoff, channel flow, infiltration, evaporation, interception, soil moisture change, groundwater recharge, and base flow, all on an hourly basis and distributed in space by subcatchments. The subcatchments are obtained through the Horton-Strahler ordering of the stream network plus considering which runoff path a certain subcatchment or stream section belongs to. Fig. 4 displays the possible runoff paths a drop of rain may travel before reaching the outlet in a fourth-order stream network, such as the Mahantango Creek watershed. Fig. 5 shows the spatial distribution of the subcatchments within the Mahantango Creek basin.

The model was calibrated with one year of data and validated over four years (Szilagyi and Parlange 1999). The correlation between observed and simulated monthly runoff for the outlet is above 0.9 for the five years combined. For the purpose of the present study the model is to be repeatedly run for 30 years at a time under present and altered climate scenarios, and the resulting direct runoff is to be compared among the subcatchments and between climate scenarios.

\section{Climate Scenarios}

The Intergovernmental Panel on Climate Change report (Watson et al. 1996) highlights that "changes in the total amount of precipitation and in its frequency and intensity directly affect the magnitude and timing of runoff and the intensity of floods and droughts; however, at present, specific regional effects are uncertain. Relatively small changes in temperature and precipitation, together with the nonlinear effects on evapotranspiration and soil moisture, can result in relatively large changes in runoff." Since

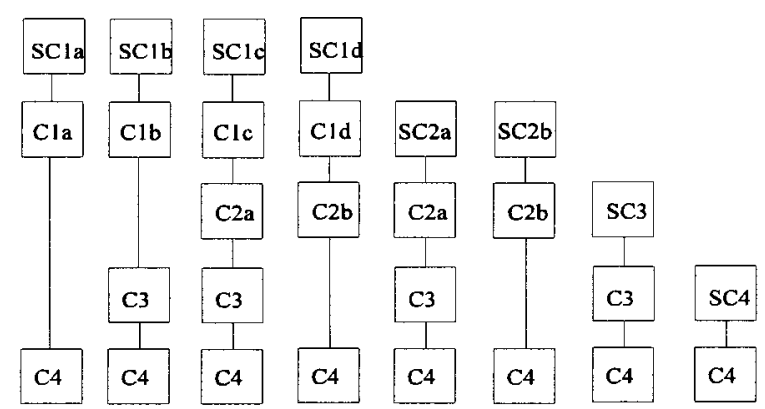

Path1 Path2 Path3 Path4 Path5 Path6 Path7 Path8

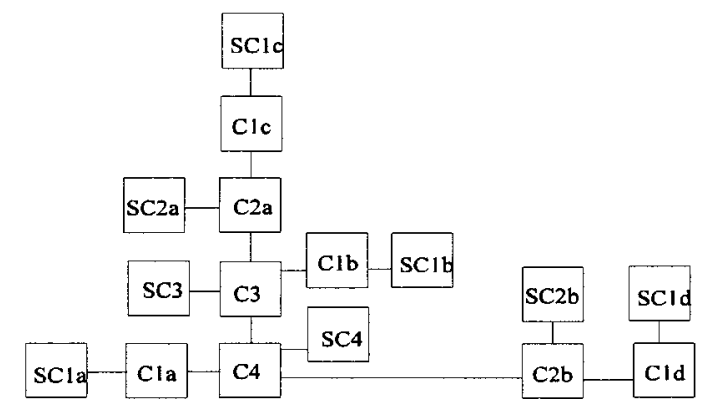

Fig. 4. Possible runoff paths for a fourth-order catchment and spatial connectivity of storage elements for Mahantango Creek Watershed, Pa: SC, subcatchment; C, channel section (from Szilagyi and Parlange 1999)

"the possible role of changes in variability is an important uncertainty in our knowledge of possible impacts of climate change" (Mearns et al. 1997), these changes in variability, although yet mostly unknown, must be included in climate change scenario studies. It is the more so because changes in climate variability may have a more profound effect on watershed dynamics than changes in the mean climate (Mearns et al. 1997).

The climate scenarios considered here belong in one of two categories by considering (1) variance change only; (2) mean and variance change. In scenario setup we follow Mearns et al. (1997) with minor modifications. In Category (1) we first change the daily temperature variance by $0.33,0.5,2$, and 3 times the baseline variance, which is represented by 30 years of generated data mentioned above. For precipitation, two scenarios are considered for variance change. In both cases the annual precipitation is left at its baseline level. First the frequency of precipitation and the scale parameter were changed; and in the second precipitation scenario the persistence $(d)$ of precipitation occurrence was modified. In both cases the parameters were changed to bring the monthly variance to $0.46,0.7,1.3$, and 1.74 times the current (baseline) level.

In the second category of scenarios first the annual mean temperature was increased (on a daily basis) by 2 and $4{ }^{\circ} \mathrm{C}$ with no change in variability. In the second scenario the variance was doubled on top of the mean increases, while in the third case scenario the variance was halved. Next, monthly precipitation was increased by a factor of 1.2 and 0.8 on a daily basis, which entails a change in the variance representing an increase in the scale parameter $b$ of the gamma distribution by a factor of about 1.2 and 0.8 . Lastly, monthly precipitation variance was further increased/decreased (by further changing the scale parameter) to 2 and 0.5 , respectively, of the baseline value. Table 1 summarizes the scenarios considered. 


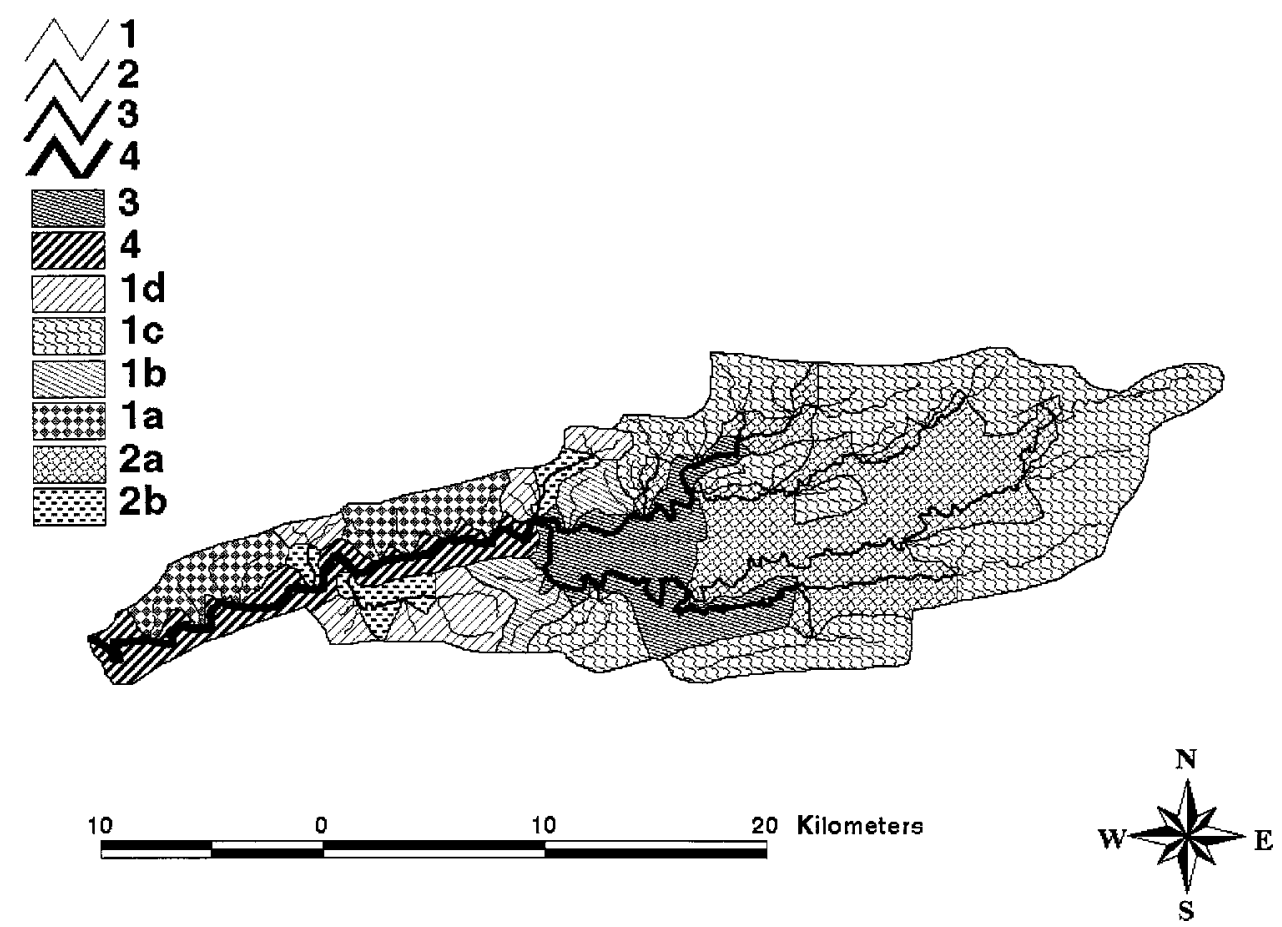

Fig. 5. Horton-Strahler ordered stream network with the corresponding subcatchments marked according to possible pathways, Mahantango Creek Watershed, Pa. (from Szilagyi and Parlange 1999)

For each scenario considered, 30 years of daily and hourly precipitation intensities as well as daily mean temperature values were generated. The watershed model was run under each scenario and the direct runoff values of each subcatchment were retained for further analysis. The analysis of runoff data started with the second year's October, the starting month of the hydrologic year. This meant 28 years of runoff data to be retained under each scenario for comparison and analysis. Excluding the first year's data in each scenario is necessary because of the unknown initial conditions (e.g., soil moisture, base flow status, direct runoff for each subcatchment) on the watershed. After running the watershed model for a whole hydrologic year, more realistic initial conditions can be expected. This is general practice in model initialization.

Table 1. Climate Scenarios Considered

\begin{tabular}{|c|c|c|c|}
\hline Case & Variable changed & $m_{\mathrm{sc}}=m$ & $V_{\mathrm{sc}}=V$ \\
\hline $\mathrm{a}$ & Daily temperature variance & Unchanged & $\times 0.33$ \\
\hline $\mathrm{b}$ & & & $\times 0.5$ \\
\hline $\mathrm{c}$ & & & $\times 2$ \\
\hline $\mathrm{d}$ & & & $\times 3$ \\
\hline $\mathrm{e}$ & Monthly precipitation variance & Unchanged & $\times 0.46$ \\
\hline $\mathrm{f}$ & & & $\times 0.7$ \\
\hline $\mathrm{g}$ & & & $\times 1.3$ \\
\hline $\mathrm{h}$ & & & $\times 1.74$ \\
\hline $\mathrm{i}$ & Persistence of precipitation occurrence & Unchanged & $\times 0.46$ \\
\hline $\mathrm{j}$ & & & $\times 0.7$ \\
\hline $\mathrm{k}$ & & & $\times 1.3$ \\
\hline 1 & & & $\times 1.74$ \\
\hline $\mathrm{m}$ & Daily mean temperature & $+2^{\circ} \mathrm{C}$ & Unchanged \\
\hline $\mathrm{n}$ & & $+4^{\circ} \mathrm{C}$ & Unchanged \\
\hline o & & $+2^{\circ} \mathrm{C}$ & $\times 2$ \\
\hline $\mathrm{p}$ & & $+4^{\circ} \mathrm{C}$ & $\times 2$ \\
\hline $\mathrm{q}$ & & $+2^{\circ} \mathrm{C}$ & $\times 0.5$ \\
\hline $\mathrm{r}$ & & $+4^{\circ} \mathrm{C}$ & $\times 0.5$ \\
\hline $\mathrm{s}$ & Monthly precipitation & $\times 1.2$ & $\times 1.4$ \\
\hline $\mathrm{t}$ & & $\times 0.8$ & $\times 0.9$ \\
\hline $\mathrm{u}$ & & $\times 1.2$ & $\times 2$ \\
\hline $\mathrm{v}$ & & $\times 0.8$ & $\times 0.5$ \\
\hline
\end{tabular}

Note: $m_{\mathrm{sc}}$ is the climate scenario mean; $V_{\mathrm{sc}}$ is the climate scenario variance, both shown in relation to the baseline values $m$ and $V$. 
Table 2. Mean Annual Precipitation and Runoff Values under Present Day Climate

\begin{tabular}{lc}
\hline Mean annual watershed precipitation & $\begin{array}{c}\text { Past } 30 \text { years } \\
(\mathrm{mm})\end{array}$ \\
\hline Measured at Newport, Pa. (1946-1998) & 1008 \\
Weather generator simulated & 1013 \\
Measured runoff (including base flow) from the & 495 \\
watershed & \\
Simulated runoff under present climate (including base & 454 \\
flow) & \\
Simulated direct runoff under present climate & 397 \\
Simulated direct runoff under present climate by subcatchments \\
Fourth order & 360 \\
Third order & 390 \\
2a & 416 \\
2b & 369 \\
1a & 427 \\
1b & 428 \\
1c & 384 \\
1d & 413 \\
\hline
\end{tabular}

\section{Model Results}

The weather-generator-simulated mean annual precipitation and the watershed-model-simulated mean annual runoff values by subcatchments under the present day climate are listed in Table 2. The weather-generator-simulated hourly precipitation intensities resulted in mean annual precipitation very close to the observed value (1946-1998) at Newport, Pa. Simulated watershed runoff, however, is about $9 \%$ less than observed mean annual runoff in the past 30 years near Dalmatia, Pa. The most likely reason is that the watershed model was calibrated with hourly precipitation values measured near Klingerstown, Pa., within the watershed. Unfortunately, long-term precipitation, needed for the daily weather generator, is not available at this location. The nearest climate station with long-term, good quality daily precipitation data was found at Newport, Pa., about $25 \mathrm{~km}$ south-west of Dalmatia. Possible difference in annual precipitation between the two stations, plus the fact that the watershed model was run with a "fictitious" series of hourly precipitation could easily explain the observed discrepancy in mean annual runoff. Note that this runoff contains the base flow contribution of the watershed, while the direct runoff values of the subcatchments do not. That is why the distinction between runoff and direct runoff is used in the table and throughout the text. Note also that in the Mahantango watershed the fourth-order subcatchment has the smallest (360 mm/year) and subcatchment $1 \mathrm{~b}$ the largest $(428 \mathrm{~mm} /$ year $)$ mean annual direct runoff values, a difference of about $15-20 \%$. These differences can be explained by the results shown in Table 3 . The fourth-order subcatchment of this watershed has the largest rooting depth (a function of both vegetation and soil type) and the largest saturated hydraulic conductivity values, while subcatchment $1 \mathrm{~b}$ is just the opposite. This means that the former can accommodate more precipitation without producing much runoff and can also transfer soil moisture toward the saturated zone faster than the latter. Also of interest is that this difference in direct runoff (although of changing magnitude) between the two subcatchments is maintained throughout the climate scenarios considered (Fig. 6).

The largest difference in direct runoff between subcatchments (Fig. 6) can be found under climate scenarios (Table I) (e) and (f), when precipitation variance was reduced. The subcatchments produced similar direct runoff responses in cases $(\mathrm{g})$ and $(\mathrm{u})$, both with enhanced precipitation variances.

So far we did not take into account that annual precipitation may change among climate scenarios. As well as the total amount of direct runoff, the portion of precipitation that becomes direct runoff under a given scenario can be of interest too. Fig. 7 compares these direct runoff ratios. The largest and smallest differences between subcatchments stay with the same climate scenarios as before.

Another interesting finding comes from Fig. 8, which shows the ratio of climate scenario direct runoff to that of present day (baseline) conditions. Direct runoff from subcatchments 4 and $1 \mathrm{~b}$ move in opposite directions under the scenarios. The subcatchment with the smallest direct runoff (i.e., 4, see Fig. 6) generally changes the least when future direct runoff is below the baseline value, and the most when future direct runoff is above baseline. The opposite is true for the subcatchment (1b) with the largest baseline runoff. This is so because the smallest-runoff-producing subcatchment has the highest rooting depth and hydraulic conductivity (this latter is important in deep percolation) and so only very large precipitation events can produce runoff, because here the soil can accommodate the most water of all the subcatchments and also can channel it deeper into the soil, where vegetation cannot access it for transpiration. A drier climate cannot affect deep percolation and thus results in small changes in runoff. In a wetter climate, however, the soil gets closer to saturation in general, so that even a smaller precipitation event can saturate the soil, resulting in runoff, and leading to relatively large changes when compared to the baseline level. This exemplifies the importance of the nonlinear effect of soil moisture on runoff generation:

Table 3. Geographic Information System-Derived Effective Porosity, Field Capacity, Saturated Hydraulic Conductivity, Rooting Depth, and Area, at Mahantango Creek, Pa.

\begin{tabular}{|c|c|c|c|c|c|}
\hline Subcatchment & $\begin{array}{l}\text { Effective } \\
\text { porosity } \\
(\%)\end{array}$ & $\begin{array}{l}\text { Field capacity } \\
(\%)\end{array}$ & $\begin{array}{l}\text { Saturated hydraulic } \\
\text { conductivity } \\
\left(10^{-6} \mathrm{~ms}^{-1}\right)\end{array}$ & $\begin{array}{l}\text { Rooting depth } \\
\text { (m) }\end{array}$ & $\begin{array}{c}\text { Area } \\
\left(\mathrm{km}^{-2}\right)\end{array}$ \\
\hline Fourth & 45.5 & 27.7 & 2.1 & 1.53 & 34 \\
\hline Third & 44.9 & 28.6 & 1.7 & 1.52 & 47 \\
\hline $2 \mathrm{a}$ & 44.4 & 28.7 & 1.6 & 1.42 & 101 \\
\hline $2 b$ & 46.3 & 28.1 & 1.9 & 1.46 & 13 \\
\hline $1 \mathrm{a}$ & 46.2 & 29.2 & 1.5 & 1.24 & 32 \\
\hline $1 b$ & 46.4 & 29.1 & 1.6 & 1.21 & 16 \\
\hline $1 \mathrm{c}$ & 44.4 & 27.9 & 1.9 & 1.53 & 152 \\
\hline $1 \mathrm{~d}$ & 47.6 & 28.8 & 1.7 & 1.20 & 28 \\
\hline
\end{tabular}




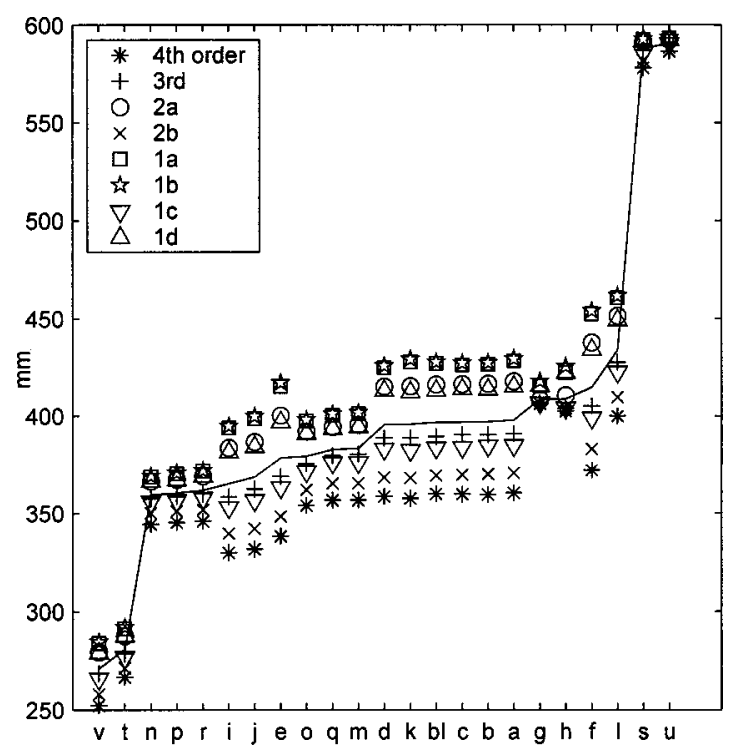

Fig. 6. Mean annual direct runoff by subcatchments $(\mathrm{mm})$ under different climate scenarios, ordered by increasing mean annual direct runoff at outlet (solid line): Letters relate to cases in Table 1; "bl" marks baseline values

the same amount of effective precipitation can produce literally no runoff when the soil is dry, but can result in large runoff response provided the soil is already close to saturation.

The largest difference between subcatchment responses can be found in cases $(\mathrm{g}),(\mathrm{s})$, and $(\mathrm{u})$, all with larger than baseline variance in precipitation plus elevated annual precipitation in the latter two cases, while the smallest differences are in cases (b) and (a), both with reduced precipitation variances.

\section{Summary and Conclusions}

The direct runoff responses of the different subcatchments of the Mahantango Creek, Pa., watershed have been simulated under a

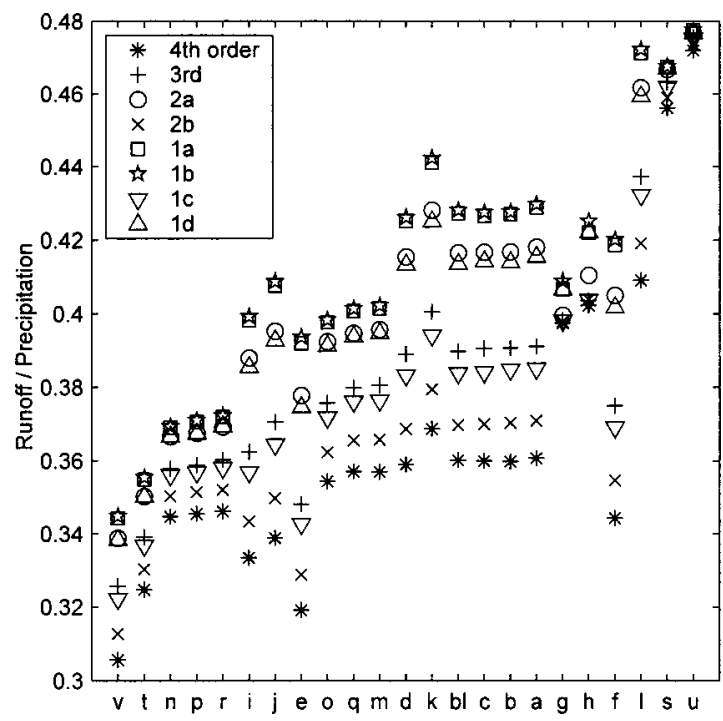

Fig. 7. Mean annual direct runoff by subcatchments as ratio of mean annual precipitation under different climate scenarios, ordered by increasing mean annual direct runoff at outlet: Letters relate to cases in Table 1; "bl" marks baseline values

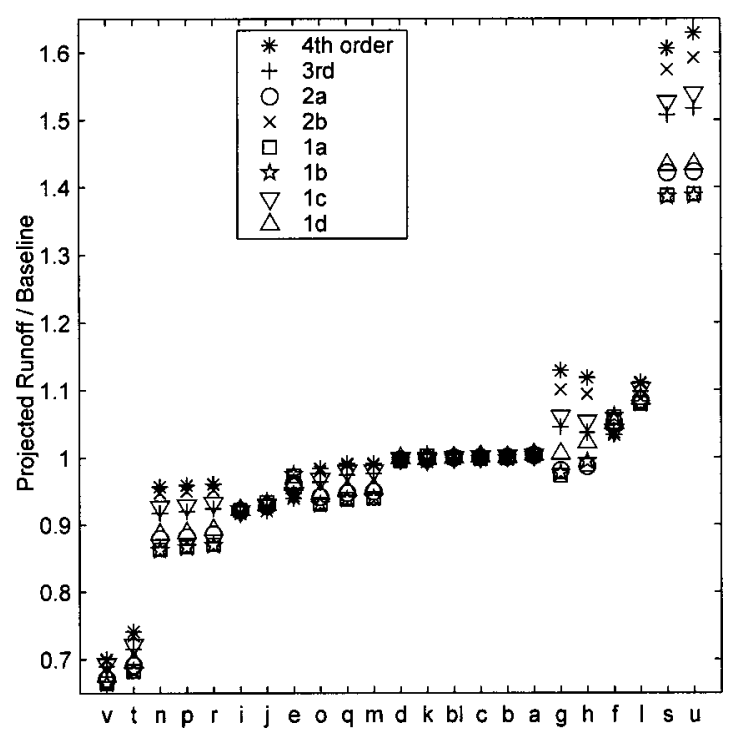

Fig. 8. Mean annual direct runoff by subcatchments under different climate scenarios as ratio of present day (bl) values, ordered by increasing mean annual direct runoff at outlet: Letters relate to cases in Table 1; "bl" marks baseline values

wide range of climate scenarios. The watershed model applied assumed no changes in land cover and land use within the catchment. Based on the watershed model results the following can be stated:

- Subcatchment direct runoff ( $\mathrm{mm} / \mathrm{year}$ ) within the watershed can differ by about $17 \%$ under the present climate. This difference may increase to $20 \%$ when daily/monthly precipitation variance is reduced;

- Subcatchments with the smallest/largest direct runoff will have the smallest/largest direct runoff under all the climate scenarios considered; and

- The relative changes in direct runoff (i.e., the ratio of subcatchment direct runoff under future and present day climate conditions) are generally the smallest for the smallest runoff "producer" (i.e., subcatchment 4) when future direct runoff of the subcatchment is less than the corresponding baseline value, and largest when future direct runoff is more than the corresponding baseline value. The opposite behavior is generally true for the subcatchment with the largest present day direct runoff (i.e., subcatchment $1 b$ ).

Our semidistributed watershed model indicates that future changes in direct runoff can most likely be expected to differ between different parts of the watershed. The majority of the climate scenarios considered produced subcatchment direct runoff in the Mahantango Creek, Pa., watershed, within $10 \%$ of the present day mean annual values. Watershed models such as the one used in this study can be best used for locating areas within a catchment with the largest/smallest expected changes in direct runoff due to climate variations. This type of information can be useful for action plans in land use management, such as planning future livestock concentrations and thus pathogen loading to surface water in the watershed.

\section{Acknowledgment}

This work has been supported by the Office of Research and Development, U.S. Environmental Protection Agency, STAR 
grant to Johns Hopkins University entitled "Integrated Assessment of the Public Health Effects of Climate Change for the United States," Award No. R824995.

\section{Notation}

The following symbols are used in this paper:

$A, B, C=$ parameters of monthly precipitation model;

$A^{*}, B^{*}, C^{*}=$ parameters of hourly power-transformed precipitation model $\left(L^{p}\right)$;

$a, b=$ shape and scale $(\mathrm{L})$ parameters of gamma distribution;

$d=$ persistence parameter;

$f=$ gamma distribution;

$g, g^{*}=$ weight parameters;

$H_{p}=$ Hinkley's index;

$h=$ hour of day;

$i, j=$ indices;

$m, m d=$ mean and median values;

$n_{i, j}=$ number of times transition from state $i$ to state $j$ occurs;

$P_{i, j}=$ probability of transition from state $i$ to state $j$

$P_{w}=$ probability of wet day in a month;

$r, r^{*}=$ precipitation $(\mathrm{L})$ and power-transformed $\left(L^{p}\right)$ precipitation amounts;

$S_{N}=$ monthly precipitation sum of $N$ days (L);

$T^{*}=$ standardized daily mean temperature $(-)$;

$t=$ day within month;

$V$, Var = variance;

$\Gamma=$ gamma value of gamma distribution;

$\varepsilon=$ normally distributed variable;

$\rho=$ autocorrelation coefficient; and

$\sigma=$ standard deviation.

\section{References}

Box, G. E. P., Jenkins, G. M., and Reinsel, G. C. (1994). Time series analysis: Forecasting and control, 3rd Ed., Prentice Hall, Englewood Cliffs, N.J.

Brutsaert, W., and Nieber, J. L. (1977). "Regionalized drought flow hydrographs from a mature glaciated plateau." Water Resour. Res., 13(3), 637-643.

Brutsaert, W., and Parlange, M. B. (1998). "Hydrologic cycle explains the evaporation paradox." Nature (London), 396, 30.

Easterling, D. R. (1999). "Development of regional climate scenarios using a downscaling approach." Climat. Change, 41, 615-634.

Fraser, R. H., Barten, P. K., and Pinney, D. A. K. (1998). "Predicting stream pathogen loading from livestock using a geographical information system-based delivery model." J. Environ. Qual., 27, 935-945.

Graczyk, T. K., Evans, B. M., Shiff, C. J., Karreman, H. J., and Patz, J. A. (2000). "Environmental and geographical factors contributing to wa- tershed contamination with Cryptosporidium parvum oocysts." Environ. Res., A82, 263-271.

Hinkley, D. V. (1977). "On quick choice of power transform." Appl. Stat., 26, 67-69.

Houghton, J. T., Meira-Filho, L. G., Callander, B. A., Harris, N., Kattenberg, A., and Maskell, K., eds. (1996). Climate Change 1995, Cambridge Univ. Press, Cambridge, U.K.

Hoxie, N. J., Davis, J. P., Vergeront, J. M., Nashold, R. D., and Blair, K. A. (1997). "Cryptosporidiosis-associated mortality following a massive waterborne outbreak in Milwaukee, Wisconsin." Am. J. Public Health, 87(12), 2032-2035.

Karl, T. R., Knight, R. W., Easterling, D. R., and Quayle, R. G. (1996). "Indices of climate change for the United States." Bull. Am. Meteorol. Soc., 77(2), 279-291.

Katz, R. W. (1996). "Use of conditional stochastic models to generate climate change scenarios." Climat. Change, 32, 237-255.

Katz, R. W., and Parlange, M. B. (1993). "Effects of an index of atmospheric circulation on stochastic properties of precipitation." Water Resour. Res., 29(7), 2335-2344.

Katz, R. W., and Parlange, M. B. (1995). "Generalizations of chaindependent processes: Application to hourly precipitation." Water Resour. Res., 31(5), 1331-1341.

MacKenzie, W. R., Hoxie, N. J., Proctor, M. E., Gradus, M. S., Blair, K. A., Peterson, D. E., Kazmierczak, J. J., Addiss, D. G., Fox, K. R., and Rose, J. B. (1994). "A massive outbreak in Milwaukee of Cryptosporidium infection transmitted through the public water supply." $N$. Engl. J. Med., 331(3), 161-167.

Manabe, S. (1997). "Study of global warming by GFDL climate models." Ambio, 26, 47-51.

Mearns, L. O., Rosenzweig, C., and Goldberg, R. (1997). "Mean and variance change in climate scenarios: methods, agricultural applications, and measures of uncertainty." Climat. Change, 35, 367-396.

Parlange, M. B., and Katz, R. W. (2000). "An extended version of the Richardson model for simulating daily weather variables." J. Appl. Meteorol., 39, 610-622.

Richardson, C. W. (1981). "Stochastic simulation of daily precipitation, temperature, and solar radiation." Water Resour. Res., 17(2), 182190.

Szilagyi, J., and Parlange, M. B. (1999). "A geomorphology-based semidistributed watershed model.” Adv. Water Resour., 23, 177-187.

U.K. Dept. of the Environment. (1990). "Cryptosporidium in water supplies." Rep., Department of Health, London.

U.S. National Research Council. (2000). "Reconciling observations of global temperature change." 〈http://books.nap.edu/catalog/9755.html .

Watson, R. T., Zinyowera, M. C., and Moss, R. H., eds. (1996). Climate change 1995, Cambridge Univ. Press, Cambridge, U.K.

Weniger, B. G., Blaser, M. J., Gedrose, J., Lippy, E. C., and Juranek, D. D. (1983). "An outbreak of waterborne giardiasis associated with heavy water runoff due to warm weather and volcanic ashfall." Am. J. Public Health, 73(8), 868-872.

Wilks, D. S. (1992). "Adapting stochastic weather generation algorithms for climate change studies." Climat. Change, 22, 67-84.

Woolhiser, D. A., Keefer, T. O., and Redmond, K. T. (1993). "Southern oscillation effects on daily precipitation in the southwestern United States." Water Resour. Res., 29(4), 1287-1295. 